\title{
Blocking of grain reorientation in self-doped alumina materials
}

- M. Suárez ${ }^{a, b}$ A. Fernández ${ }^{a, b}$, J.L. Menéndez ${ }^{a}$, J. Ramírez-Ricoc ${ }^{c}$, R. Torrecillas ${ }^{a}$

- a Department of Nanostructured Materials, Centro de Investigación en Nanomateriales y Nanotecnología (CINN), Principado de Asturias, Consejo Superior de Investigaciones Científicas (CSIC), Universidad de Oviedo (UO), Parque Tecnológico de Asturias, 33428 Llanera, Asturias, Spain

- ${ }^{\mathrm{b}}$ Fundación ITMA, Parque Tecnológico de Asturias, 33428 Llanera, Spain

- c Dpto. Física de la Materia Condensada-ICMSE, Universidad de Sevilla-CSIC, Avda. Reina Mercedes s/n, 41012 Sevilla, Spain

Alumina nanoparticles $10-20 \mathrm{~nm}$ in diameter were nucleated on alumina particles, $150 \mathrm{~nm}$ average diameter, by a colloidal route followed by calcination. It is shown that after sintering, the final grain size is up to $20 \%$ smaller due to the addition of the alumina nanoparticles. Electron backscattered diffraction analysis shows that whereas a correlation in the relative crystalline orientations between neighbouring grains exists in the pure materials, the addition of alumina nanoparticles results in a random crystalline orientation.

Keywords Ceramics; Grain growth; Self-doping; Electron backscattering diffraction (EBSD)

Nanostructured materials are a relatively new kind of material in which a grain size in the nanometer range, or nanometer-sized second phases dispersed in a matrix, confer different properties compared to their bulk counterparts. Improvements in physical properties related to the existence of nanometer-sized grains are given by the Hall-Petch law [1] and [2] and various examples have been reported [3], [4] and [5]. There have been many attempts reported in the literature to make fully dense monolithic alumina with a grain size in the nanometer/submicron range. Various approaches have been developed, including two-step sintering [6], [7] and [8], non-conventional sintering [9] and [10], changing the sintering atmosphere [11] and [12] or using dopants such as $\mathrm{MgO}, \mathrm{Y} 2 \mathrm{O}$, SiC, etc., which were shown to perform as effective grain growth inhibitors for Al2O3[13], [14], [15], [16], [17], [18], [19], [20] and [21].

However, in the latter case, the introduction of these additives, even at low concentrations, can result in the formation of secondary phases with a different refractive index compared to that of the alumina matrix, and therefore light scattering takes place, impeding the production of transparent alumina materials. In addition, doping with silica leaves a glass residue that reduces the mechanical performance of the material.

Alumina-doped alumina powders have been shown to be an effective way to minimize grain growth in sintered materials [22]. It is the aim of this work to show that a self-doping process makes it possible to block grain reorientation during sintering and hence obtain a finer microstructure in doped alumina. 
A colloidal method was used [23] to dope pure commercial nanocrystalline alumina powder TM-DAR (average grain size $\sim 160 \mathrm{~nm}$, specific surface area $14.5 \mathrm{~m} 2 \mathrm{~g}-1$ and $99.99 \%$ purity) with aluminium ethoxide (97\% Sigma-Aldrich). The doping was carried out under an argon atmosphere by dissolving an appropriate quantity of aluminium ethoxide in anhydrous ethanol (99.97\%) to form alumina doped with $10 \mathrm{wt} . \%$ alumina coming from the aluminium ethoxide (i.e. self-doping), and then adding the solution dropwise to an alumina/ethanol slurry. The slurry was first dried under magnetic stirring at $60-70{ }^{\circ} \mathrm{C}$ and subsequently in air at $120{ }^{\circ} \mathrm{C}$ in order to eliminate any traces of alcohol. The dried powders were subsequently crushed in a high-purity alumina mortar to remove the agglomerates resulting from the drying process, and sieved using a $63 \mu \mathrm{m}$ mesh. The powders were thermally etched at $800^{\circ} \mathrm{C}$ for $2 \mathrm{~h}$ in order to remove the organic residuals and sieved again to obtain deagglomerated powders. These powders were cold isostatically pressed (CIP) at $200 \mathrm{MPa}$, and sintered in air at different temperatures $\left(1160-1500^{\circ} \mathrm{C}\right)$ and for different holding times $(0.5-2 \mathrm{~h})$.

The density of the specimens was measured using picnometry powder equipment (GeoPyc 1360, MICROMERITICS ${ }^{\circledR}$ ) and by the Archimedes method, and normalized using a theoretical density of $3.987 \mathrm{~g} \mathrm{~cm}-3$ [24]. Finally, the microstructure and the grain size of the sintered samples were characterized by scanning electron microscopy (SEM; Zeiss DSM 950) of the fracture surfaces.

The crystal orientations of the grains in the sintered materials were assessed by electron backscattered diffraction (EBSD) measurements. Samples of both pure alumina and $10 \%$ aluminium ethoxide-doped alumina conventionally sintered for $1 \mathrm{~h}$ at $1235^{\circ} \mathrm{C}$ were prepared using metallographic procedures that involved polishing up to $1 \mu \mathrm{m}$ in a diamond slurry and a final polishing/etching step with $20 \mathrm{~nm}$ colloidal silica. Diffraction patterns were acquired using an EBSD CCD camera (Oxford Instruments Crystal-300) attached to a field emission gun scanning electron microscope (LEO Gemini-1530). Due to charging under the electron beam, it was not possible to obtain detailed orientation maps, but instead evenly spaced points were measured and indexed over a $\sim 300 \times 300 \mu \mathrm{m} 2$ area. This was sufficient to reconstruct the orientation distribution functions (ODFs) of alumina in both samples. Raw EBSD data was imported into the MTEX [25] software toolbox for MATLAB, where orientation distribution function (ODF) reconstruction was performed using a Fourier technique with a $10^{\circ}$ convolution kernel. Datasets were rotated to make $\left(\begin{array}{llll}0 & 0 & 0 & 1\end{array}\right)$ poles parallel to the normal direction for ease of visualization and $\left(\begin{array}{llll}0 & 0 & 0 & 1\end{array}\right)$ and pole figures were calculated.

Figure 1 shows TEM images of the pure (Fig. 1a) and doped alumina (Fig. 1b) powders after calcination at $800^{\circ} \mathrm{C}$. Figure 1a shows pure TM-DAR alumina particles with clean and faceted surfaces. On the other hand, nanoparticles with diameters around 10-20 nm have nucleated on top of the TM-DAR alumina particles after calcination at $800{ }^{\circ} \mathrm{C}$ for $2 \mathrm{~h}$ of the alumina doped with aluminium ethoxide (Fig. 1b). The nucleated particles also show a hexagonal shape, suggesting that they have already transformed to $\alpha$-Al2O3 after calcination at $800{ }^{\circ} \mathrm{C}$, far below the $\alpha$ phase formation temperature $\left(\sim 1200{ }^{\circ} \mathrm{C}\right)$. Therefore, doping the alumina powders with an aluminium precursor followed by calcination can modify the surface of the raw alumina powders. BET surface area analysis shows an increase in the surface of the selfdoped powders from 13.7 (Taimei, TM-DAR) to $22.3 \mathrm{~m} 2 \mathrm{~g}-1$. 
Figure 2 shows SEM images corresponding to fracture surfaces of pure and doped alumina, conventionally sintered at different temperatures, 1300 and $1400{ }^{\circ} \mathrm{C}$, for $2 \mathrm{~h}$. No relevant changes in the microstructure between pure and doped samples are observed at low sintering temperatures (Fig. 2a and b). The micrographs also show rounded grain boundaries, indicating that sintering is still at an early stage. The situation is different at the higher sintering temperature, $1400^{\circ} \mathrm{C}$ : the grain size reaches the micron size $(1.76 \pm 0.49 \mu \mathrm{m})$ for pure alumina (Fig. 2c), whereas it remains in the submicron range $(0.48 \pm 0.22 \mu \mathrm{m})$ in the doped material (Fig. 2d).

In order to gain a deeper understanding of the microstructural features, EBSD analysis was carried out on conventionally sintered powders. Pole figures were obtained from EBSD measurements and are shown in Figure $3 a$ for pure alumina and in Figure $3 \mathrm{~b}$ for $10 \%$ aluminium ethoxide-doped alumina sintered for $1 \mathrm{~h}$ at $1235^{\circ} \mathrm{C}$. It is clear that, while the texture of the ethoxide-doped alumina is mostly random and closely resembles that of a purely polycrystalline material, the crystallographic texture of pure alumina shows a greater degree of preferred orientation, as is evidenced by the intensity maxima in the pole figures shown in Figure 3a. This observation was confirmed by the calculation of the texture index of the ODF, which was 2.38 for pure alumina and 1.22 for ethoxide-doped alumina. The texture index is a global measure of the degree of texture in a material and is equal to 1 for a material consisting of randomly oriented crystallites.

Additionally, the 6-fold multiplicity of the reflections (as opposed to 3-fold symmetry of the Al2O3 lattice due to lack of centrosymmetry) probably reflects the presence of basal twins in the pure alumina, characterized by a $60^{\circ}$ degree rotation around the $\left[\begin{array}{llll}0 & 0 & 0 & 1\end{array}\right]$ direction. In basal twins the oxygen sublattice remains almost unaltered across the interface [26]. Due to the high number of coincident sites, basal twins constitute low-energy grain boundaries, as often observed in sintered pure alumina [27]. Their absence in ethoxide-doped alumina can therefore be explained if grain reorientation in the early sintering stage is suppressed for the self-doped alumina.

This difference between the arrangement of the alumina grains can be explained by assuming that the alumina particles undergo a reorientation during sintering [28], [29], [30] and [31]: in the case of pure alumina, a reduction of energy at the grain boundaries takes place due to the formation of solid-solid interfaces through planes with similar orientation. At higher temperatures, diffusion through grain boundaries is promoted and grain growth is accelerated considerably. Initially, the green body may be considered as a three-dimensional homogeneous distribution of crystals with random orientation and random distribution of contact points between crystals (particles). In this case, the total energy of the system will be the volume energy plus the free surface area plus the energy of the solid-solid interfaces. At low temperatures, the only contribution to a total energy reduction of the system will come from the reduction in the solid-gas free energy associated with the different alumina surfaces by increasing the number of solid-solid contacts between crystals. This reduction will be favoured when the surfaces coming into contact have the same orientation. In fact, contact between two planes with the same orientation is the most effective way to reduce the free energy of the system when the temperature is so low that thermally activated diffusion mechanisms cannot take place. Therefore, at low temperatures, alumina particles slip to 
reduce the total energy of the system by forming grain clusters with the same orientation. These grains with the same plane orientation will form low-energy grain boundaries. During sintering, these interfaces readily disappear, as only very low ion mobility (only short diffusion paths) is required for this to happen, leading to grain growth. Once these agglomerates are formed, sintering continues via normal growth mechanisms.

However, the situation is different in the doped alumina, where the presence of the $\alpha$-alumina nanocrystals at low temperatures inhibits grain reorientation, as opposed to the pure alumina case, during the first steps of sintering. Therefore, no energy reduction can take place as particles are not able to join through similar faces. Consequently, this implies that during the early stages of sintering, a given grain keeps a random crystalline orientation with respect to its neighbours. When the temperature is high enough to allow atomic diffusion mechanisms to become active, sintering takes place and the final microstructure is kept finer. Although shown for a particular system, such as alumina, the method proposed is general and may have implications for other systems in which control of grain growth during sintering is required. This route explains the finer microstructure in the doped alumina.

We have therefore shown that doping with aluminium ethoxide is an efficient way to minimize alumina grain growth during sintering.

In conclusion, it has been shown that by modifying the surface of the alumina particles after a self-doping process, it is possible to block grain reorientation during sintering. Finally, this selfdoping method has been found to be an effective means to reduce the average grain size without introducing secondary phases with a refractive index different to that of the matrix.

\section{Acknowledgements}

The authors want to acknowledge the Spanish Ministry of Education and Science and UE for funding through projects MAT2006-01783 and NMP3-CT-2005-515784. M.S. wants to acknowledge the I3P program for a PhD grant. J.R.-R. acknowledges financial support from the Junta de Andalucía. EBSD was performed at the CIC of the University of Granada, Spain. 


\section{References}

1. E.O. Hall

Proc. Phys. Soc. London Sect. B, 64 (1951), p. 747

2. N.J. Petch

J. Iron Steel Inst., 174 (1953), p. 25

3. A. Krell

Mater. Sci. Eng. A, 245 (1998), p. 277

4. K. Kubota, M. Mabuchi, K. Higashi

J. Mater. Sci., 34 (1999), p. 2255

5. P.Y. Lee, T. Yano

J. Eur. Ceram. Soc., 24 (2004), p. 3359

6. F.J.T. Lin, L.C. DeJonghe

J. Am. Ceram. Soc., 80 (1997), p. 2269

7. R.J. Sung, D.S. Kim, S.A. Ji, J.S. Park, S.W. Kim

Mater. Sci. Forum, 510-511 (2006), p. 822

8. J.G. Li, Y.P. Ye

J. Am. Ceram. Soc., 89 (2006), p. 139

9. Z.J. Shen, M. Johnsson, Z. Zhao, M. Nygren

J. Am. Ceram. Soc., 85 (2002), p. 1921

10. J.P. Cheng, D. Agrawal, Y.J. Zhang, R. Roy

Mater. Lett., 56 (2002), p. 587

11. K. Kobayashi, M. Kaneno, US Patent No. 3792142, 1974.

12. A. Auriol, P. Tritten, US Patent No. 4031177, 1977.

13. S.J. Bennison, M.P. Harmer

J. Am. Ceram. Soc., 66 (1983), p. C90

14. S.J. Bennison, M.P. Harmer

J. Am. Ceram. Soc., 68 (1985), p. C22

15. R.C. McCune, W.T. Donlon, R.C. Ku 
J. Am. Ceram. Soc., 69 (1986), p. C196

16. H. Erkalfa, Z. Misirli, T. Baykara

J. Mater. Process. Technol., 62 (1996), p. 108

17. L.N. Satapathy

Interceramics, 48 (1999), p. 188

18. S.I. Bae, S. Baik

J. Mater. Sci., 28 (1993), p. 4197

19. S.I. Bae, S. Baik

J. Am. Ceram. Soc., 77 (1994), p. 2499

20. S.I. Bae, S. Baik

J. Am. Ceram. Soc., 80 (1997), p. 1149

21. L.C. Stearns, M.P. Harmer

J. Am. Ceram. Soc., 79 (1996), p. 3013

22. M. Suárez, A. Fernández, J.L. Menéndez, R. Torrecillas, C. Pecharromán, ES Patent 2007[02690], 2007.

23. M. Schehl, L.A. Díaz, R. Torrecillas

Acta Mater., 50 (2002), p. 1125

24. J.D. Cawley, Binary Oxide Ceramics: Al2O3, ZrO2. Structure and Properties, Encyclopedia of Materials: Science and Technology, pp. 524-533, ISBN: 0-08-0431526.

25. R. Hielscher, H. Schaeben

J. Appl. Cryst., 41 (2008), p. 1024

26. K.J. Morrisey, C.B. Carter

J. Am. Ceram. Soc., 67 (1984), p. 292

27. D.W. Susnitzky, C.B. Carter

J. Am. Ceram. Soc., 73 (1990), p. 2485

28. J. Chen, P. Shen

Scripta Mater., 37 (1997), p. 1287

29. S.R. Wang, P. Shen 
Mater. Sci. Eng. A, 251 (1998), p. 106

30. K.T. Lin, P. Shen

Mater. Sci. Eng. A, 270 (1999), p. 125

31. K.C. Yang, P. Shen, D. Gan

J. Eur. Ceram. Soc., 28 (2008), p. 1169 


\section{Figure captions}

Figure 1. TEM images showing pure alumina grains (a) and alumina grains doped with aluminium ethoxide (b) after calcination at $800^{\circ} \mathrm{C}$ for $2 \mathrm{~h}$

Figure 2. Pure (left column) and doped (right column) alumina conventionally sintered at 1300 ( $a$ and $b$ ) and $1400{ }^{\circ} \mathrm{C}$ (c and d) with $2 \mathrm{~h}$ holding time

Figure 3. Representative pole figures reconstructed from EBSD data. Two reflections of $\alpha-\mathrm{Al}_{2} \mathrm{O}_{3}$ are shown: (a) pure alumina and (b) alumina doped with $10 \%$ aluminium ethoxide and conventionally sintered for $1 \mathrm{~h}$ at $1235^{\circ} \mathrm{C}$. White regions correspond to orientations where density is equal to that of random distribution of orientations. The scale is the same in both cases for ease of comparison. 
Figure 1

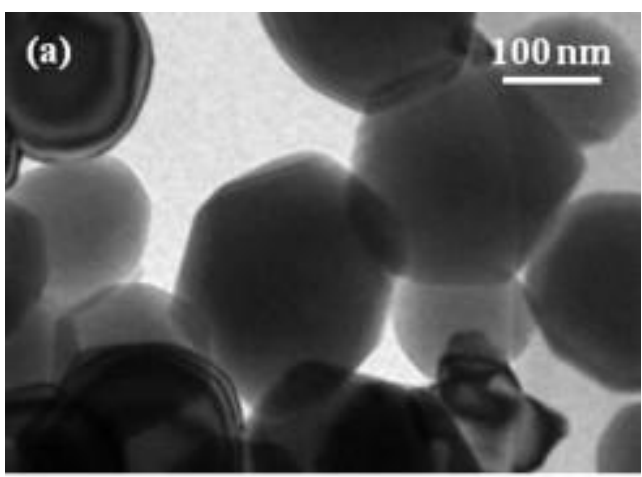

(b) $2 \underline{n m}$

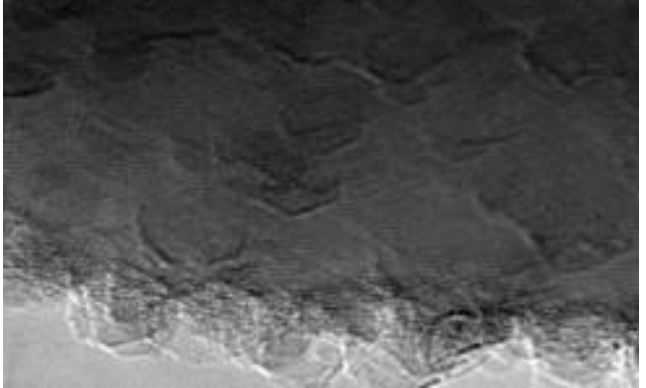


Figure 2
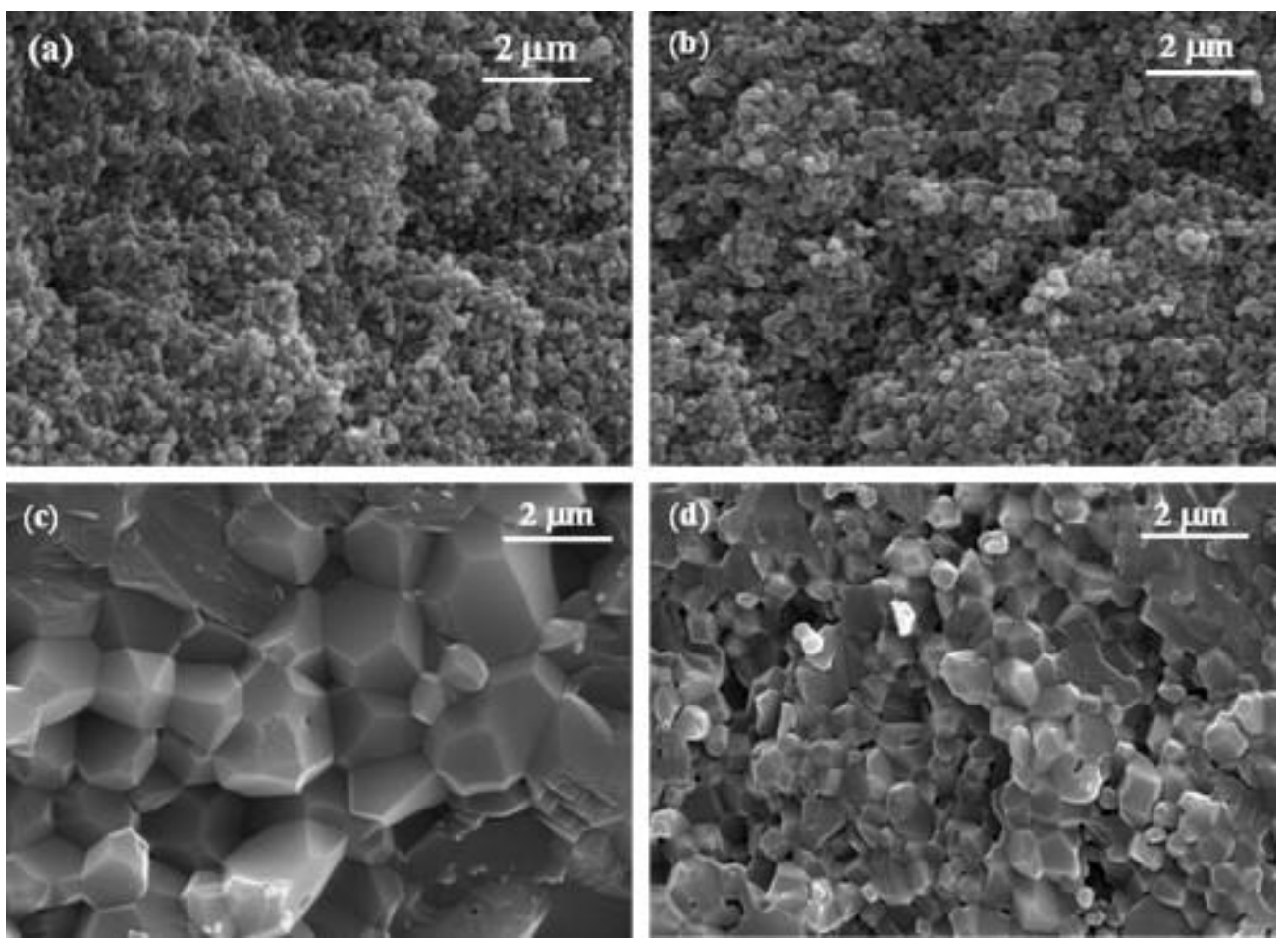
Figure 3

a

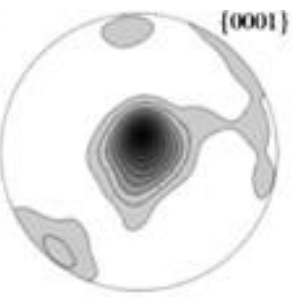

b

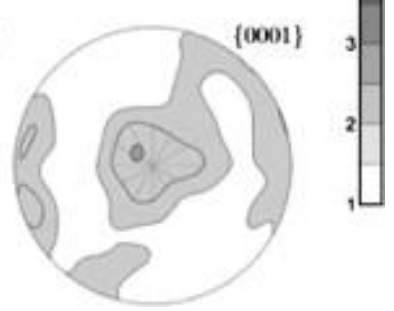

